CLINICAL PRACTICE

\title{
Adrenaline and amiodarone dosages in resuscitation: Rectifying misinformation
}

\author{
M Botha, M Wells, R Dickerson, L Wallis, M Stander; the ARREST Special Interest Group of EMSSA \\ $M$ Botha, M Wells and L Dickerson are from the Division of Emergency Medicine, University of the Witwatersrand, Johannesburg, South Africa. \\ $L$ Wallis and M Stander are from the Divisions of Emergency Medicine, University of Cape Town and University of Stellenbosch, South Africa. The \\ authors are members of the Advocacy for Resuscitation Research Education Science and Training (ARREST) Special Interest Group of the Emergency \\ Medicine Society of South Africa (EMSSA).
}

Corresponding author: M Botha (resuscitation@vodamail.co.za)

Despite the recognition of specialists in emergency medicine and the professionalisation of prehospital emergency care, international guidelines and consensus are often ignored, and the lag between guideline publication and translation into clinical practice is protracted. South African literature should reflect the latest evidence to guide resuscitation and safe patient care. This article addresses erroneous details regarding life-saving interventions in the South African Medicines Formulary, 10th edition.

S Afr Med J 2013;103(10):713-714. DOI:10.7196/SAMJ.7347

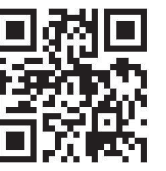

Until recently, training and education in resuscitation have received little attention in South Africa (SA). Despite the recognition of specialists in emergency medicine and the professionalisation of prehospital emergency care, international guidelines and consensus are often ignored and the lag between guideline publication and translation into clinical practice is protracted. South African literature should reflect the latest evidence to guide resuscitation and safe patient care. However, in the current South African Medicines Formulary (SAMF) (10th edition), ${ }^{[1]}$ detail regarding these life-saving interventions is missing and erroneous, and incongruent with current international consensus. Most drugs that are commonly used during the management of cardiac arrest are reported incorrectly.

\section{Adrenaline in cardiac arrest}

The SAMF advocates 'IV injection, $1 \mathrm{mg}(10 \mathrm{ml}$ 1:10 000) every 5 cycles of CPR' in an adult patient. This statement is incorrect. Five cycles of cardiopulmonary resuscitation (CPR) implies five cycles of 30 compressions followed by 2 ventilations. If performed at the required rate and efficiency, these 5 cycles would be complete in 2 minutes. Giving adrenaline every 2 minutes is double the dose recommended by the international guidelines; the use of 'megadose' adrenaline is potentially harmful and should not be used. The administration of $1 \mathrm{mg}$ intravenous (IV)/intraosseous (IO) adrenaline is reasonable every 3 - 5 minutes during adult cardiac arrest. $^{[2,3]}$

For paediatric cardiac arrest, the SAMF correctly recommends adrenaline at $0.1 \mathrm{ml} / \mathrm{kg} /$ dose of a 1:10 000 solution; however, this should be given every 3 - 5 minutes rather than the 5 - 15 minutes cited. $^{[1,4]}$ Furthermore, the SAMF prescribes an IV infusion of $0.1-1 \mathrm{mcg} / \mathrm{kg} / \mathrm{minute}$ as an alternative in cardiac arrest. IV bolus administration is the preferred practice. ${ }^{[4]}$

Adrenaline for asthma and anaphylaxis According to the $S A M F$, adrenaline can be administered slowly via the IV route using $3-5 \mathrm{ml}$ of a 1:10 000 solution $(1 \mathrm{mg} / 10 \mathrm{ml})$ in asthma and acute anaphylaxis. This is extremely unsafe. For patients not in cardiac arrest, an IV adrenaline bolus dose of no more than $0.05-0.1 \mathrm{mg}$ is recommended ${ }^{[5]}$ the $S A M F$ suggests a much larger dosage which is not supported by any international guideline.

\section{Amiodarone in cardiac arrest}

The SAMF states that 'in acute resuscitation, slow IV boluses of $150 \mathrm{mg}$ may be given.' This statement is not in accord with the International Liaison Committee on Resuscitation (ILCOR) and American Heart Association (AHA) treatment recommendations. If amiodarone is administered for refractory ventricular fibrillation or pulseless ventricular tachycardia, then a $300 \mathrm{mg}$ bolus should be given 2 minutes after the first adrenaline dose. Should the patient remain in a shockable rhythm following a further 2 minutes of CPR, a defibrillation shock, another adrenaline dose, and another 2 minutes of CPR ( 5 cycles of 30:2), then a further $150 \mathrm{mg}$ IV amiodarone may be administered.

\section{Atropine in asystole}

The $S A M F$ states that atropine may be administered to patients in asystole. This has not been part of the ILCOR recommendations since 2010. It should not be used.

\section{Conclusion}

The SAMF is a well-respected benchmark and vade mecum for the SA healthcare provider. It is vital that the text is correct, contemporary and follows international clinical guidelines to ensure consistent and safe patient care, particularly in the management of patients in extremis.

\section{Response from the editors of the SAMF}

Dawn Rossiter, Editor of the SAMF, and Marc Blockman, the Managing Editor, note the statement from the ARREST Special Interest Group of EMSSA.

Recommendations from the 2010 AHA guidelines for cardiopulmonary resuscitation and emergency cardiovascular care ${ }^{[2]}$ 


\section{FORUM}

will be reflected in the next edition due for publication in January 2014.

The aim of the $S A M F$ is to promote safe and rational drug therapy, and we welcome all comments and constructive criticism.

1. Division of Clinical Pharmacology, Faculty of Health Sciences, University of Cape Town. South African Medicines Formulary. 10th ed. Rossiter D, ed. Cape Town: Health and Medical Publishing Group, 2012:132-135.

2. Neumar RW, Otto CW, Link MS, et al. Part 8: Adult advanced cardiovascular life support: 2010 American Heart Association guidelines for cardiopulmonary resuscitation and emergency cardiovascular care.
Circulation 2010;122:S729-S767. [http://dx.doi.org/10.1161/CIRCULATIONAHA.110.970988]

3. Deakin CD, Morrison LJ, Morley PT, et al. Part 8: Advanced life support: 2010 internation 3. Deakin CD, Morrison LJ, Morley PT, et al. Part 8: Advanced life support: 2010 international treatment recommendations. Resuscitation 2010;81(Suppl 1):e93-e174. [http://dx.doi.org/10.1016/j. resuscitation.2010.08.027]

4. de Caen AR, Kleinman MER, Chameides L, et al. Part 10: Paediatric basic and advanced life support: 2010 international consensus on cardiopulmonary resuscitation and emergency cardiovascul (2010:81:e213-e259. [http.//dxdol org/10.1016/j.resuscitation.2010.08.028]

5. Vanden Hoek TL, Morrison LJ, Shuster M, et al. Part 12: Cardiac arrest in special situations (2010 Aneran Hears

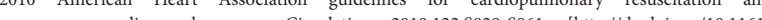
A.110.971069]

Accepted 11 August 2013 